\title{
Kinerja Simpang Empat Bersinyal Jalan Depati Purbo Dan Jalan KH. A. Majid
}

\author{
William Noferi, Amsori M. Das*, Ari Setiawan \\ Teknik Sipil Universitas Batanghari Jambi \\ *Correspondence email: amsorimd@gmail.com
}

\begin{abstract}
Abstrak. Simpang Empat bersinyal Jalan Depati Purbo dan Jalan KH. Merupakan salah satu simpang bersinyal di Kota Jambi. Arus lalu lintas yang melalui simpang tersebut adalah arus lalu lintas menuju ke Provinsi Riau, Kabupaten Muaro Jambi, Kabupaten Batanghari dan Kota Jambi, yang merupakan daerah komersial. Simpang Empat Jalan Depati Purbo dan Jalan KH A. Majid mempunyai potensi yang dapat menimbulkan kemacetan karena banyaknya kendaraan sepeda motor, kendaraan ringan dan kendaraan berat yang melewati simpang tersebut dan tidak berfungsi lampu lalu lintas dengan baik. Jenis data yang digunakan untuk keperluan analisis adalah data primer dan data sekunder. Pencatatan arus lalu lintas dibagi dalam kendaraan ringan, kendaraan berat, sepeda motor dan kendaraan tak bermotor yang dipisahkan tiap interval waktu 15 menit pada kondisi jam puncak pagi, siang dan sore pengambilan data arus lalu lintas dilakukan pada hari Minggu 09 Agusus 2020 dan Senin 10 Agustus 2020. Data tersebut dianalisis untuk mencari kapasitas, derajat kejenuhan, panjang antrian, kendaraan terhenti dan tundaan dengan metode Manual Kapasitas Jalan Indonesia 1997. Berdasarkan hasil analisis diketahui bahwa arus lalu lintas yang melewati Simpang Empat Jalan Depati Purbo dan Jalan KH. A. Majid adalah padat. Jam puncak terjadi pada Jl. Jambi-Riau sebesar 1283.8 smp/jam pada tanggal 10 Agustus 2020 pukul 16.00 wib-19.00 wib. Dengan nilai waktu siklus sebesar 117 detik. Kinerja simpang dapat dilihat dari nilai kapasitas, derajat kejenuhan simpang yang cukup tinggi, panjang antrian, jumlah kendaraan terhenti , tundaan.
\end{abstract}

Kata Kunci: Kinerja Simpang Empat Bersinyal Jalan Depati Purbo dan Jalan KH. A. Majid.

\section{PENDAHULUAN}

Jambi adalah Provinsi di Indonesia yang terletak di pesisir Timur di bagian tengah Pulau Sumatera, pesatnya pertumbuhan penduduk ini yang akan memicu peningkatan aktivitas penduduk terutama di daerah perkotaan. Kota Jambi merupakan pusat pemerintah, ekonomi, sosial, dan budaya, aktivitas penduduk perkotaan terjadi akibat adanya kawasan menarik dan kawasan bangkitan yang meningkatnya tuntunan lalu lintas (Traffic Demand), peningkatan tuntunan lalu-lintas akan menambah masalah kemacetan lalu-lintas pada ruas jalan dan persimpangan jalan.

Dengan pesatnya perkembangan Kota Jambi yang menjadi pusat aktivitas, membutuhkan dukungan prasarana yang memadai, salah satu prasarana yang di maksud adalah prasarana jalan raya, seiring dengan meningkatnya pertumbuhan penduduk dan perkembangan. Kota serta aktivitas manusia dan ruang lingkup kehidupan, maka tidak dapat dipungkiri lagi saat ini hampir di setiap Kota Jambi dihadapkan pada problem transportasi yang cukup serius, antara lain adalah kemacetan dan tundaan pada ruas-ruas jalan terutama di persimpangan jalan jalan Depati Purbo dan Jalan KH. A. Majid terutama pada jam sibuk.

Persimpangan merupakan bagian yang sukar dan rumit dari suatu sistem jalan raya dan disinilah tempat pertemuaan ruas-ruas jalan yang berpotensi terjadi konflik lalu lintas, karena disebabkan oleh simpang yang berfungsi sebagai tempat kendaraan melakukan perubahan arah pergerakan arus lalu lintas. Ketidak seimbangan antara fasilitas umum penunjangan lalu lintas dengan peningkatan jumlah arus lalu lintas akan memberi dampak terjadinya kemacetan lalu lintas yang akan terjadi di persimpangan.

Simpang Empat jalan Jalan Depati purbo dan Jalan KH. A. Majid, merupakan salah satu simpang di Kota Jambi yang yang memiliki empat lengan yang terdiri dari Jalan Depati Purbo, Jalan KH. A. Majid, Jalan Jambi-Riau dan Jalan Jambi-Muara Bulian. Permasalahan pada simpang tersebut selain kemacetan saat jam sibuk dan tidak berfungsinya lampu lalu lintas tersebut dengan baik, yang mengakibatkan para pengguna simpang tersebut sering mengalami kecelakaan kendaraan yang tidak mentaati rambu-rambu lalu lintas, terjadinya antrian pada jam-jam sibuk dan waktu siklus yang tidak sesuai pada simpang tersebut

Dengan permasalahan yang ada diatas, maka penulis ingin mengkaji dengan mengambil judul tugas akhir"Kinerja Simpang Empat Bersinyal Jalan Depati Purbo Dan Jalan KH. A. Majid".

\section{Landasan Teori \\ Pengertian Simpang}

Persimpangan merupakan bagian yang tidak terpisahkan dari semua sistem jalan. Ketika berkendaraan di dalam kota, orang dapat melihat bahwa kebanyakan jalan di daerah perokotaan biasanya memilki persimpangan, di mana pengemudi dapat memutuskan untuk jalan terus atau berbelok dan pindah jalan (Khisty, Jotin C. B. Kent Lall, 2005: 274). 


\section{Jenis-Jenis Simpang \\ Simpang Sebidang}

Persimpangan sebidang adalah pertemuan dua jalan ruas lebih secara sebidang tidak saling bersusun. Pertemuan ini direncanakan dengan tujuan untuk mengalirkan atau melawan lalu lintas dengan lancar serta mengurangi kemungkinan terjadinya kecelakaan/pelangaran sebagai akibat dari titik konflik yang ditimbulkan dari adanya pergerakan bermotor, pejalan kaki, sepeda dan faslitas-fasilitas lain (Ikrar Tulus, Muh, 2018:7).

\section{Simpang Tidak Sebidang}

Simpang tidak sebidang adalah pertemuan dua arus lebih saling bertemu tidak dalam satu bidang tetapi salah satu ruas berada di atas atu bawah ruasjalan lain Simpang tidak sebidang (interchange) biasanya menyediakan gerakan membelok tanpa berpotongan, maka dibutuhkan tikungan yang besar dan sulit serta biaya yang mahal (Ikrar Tulus, Muh, 2018: 8).

\section{Karakter Sinyal Lalu Lintas}

Untuk sebagai besar fasiltas jalan, kapasitas dan perilaku lalu-lintas terutama adalah fungsi dari keadaan geometrik dan tuntunan lalu-lintas. Dengan mengunakan sinyal, perancang/insinyur dapat mendestribusikan kapsitas kepada berbagai pendekat melalui pengalokasikan waktu hijau pada masing-masing pendekat. Maka dari itu untuk menghitung kapasitas dan perilaku lalu-lintas, pertama-tama perlu ditentukan fase dan waktu sinyal yang paling sesuai untuk kondisi yang ditinjau.Penguna sinyal dengan lampu tiga warna (hijau, kuning, merah) diterapakan untuk memisahkan lintasan dari gerakan-gerakan lalu-lintas yang bertentangan dalam dimensi waktu (MKJI,1997: 2).

\section{METODE}

\section{Pengumpulan Data}

Pengumpulan data merupakan langkah awal setelah persiapan dalam proses pelaksanaan evaluasi dan perencanaan yang sangat penting, dalam tahap pengumpulan data dilakuan melalui beberapa tahap yaitu:

1. Survei kelapangan

Survei kelapangan merupakan tahap pertama untuk mendapatkan informasi yang ada dilapangan

a. Meninjau tempat lokasi survei.

b. Menentukan waktu pengamatan dilapangan penelitian.

c. Menetukan tempat surveyor agar mendaptkan tempat yang nyaman dan aman untuk surveyor

2. Cara kerja saat survei dilapangan

Demi mendapatkan data yang lebih baik saat melakukan survei dilapangan maka disni menjelasakan cara kerja kepada surveyor

a. Tata cara kerja survei arus lalu lintas yang dibagi dalam interval waktu setiap 15 menit dengan mengambil waktu pagi pukul 07.00-10.00 wib, waktu siang pukul 11.00-14.00 wib dan waktu sore pukul 16.00-19.00 wib dengan pembagian arah lalu lintas, jenis kendaraan yang sesuai dengan formulir survei yang dimiliki surveyor dan penempatan disetiap persimpngan surveyor dengan jumlah surveyor 12 orang

b. Tata cara kerja survei geometrik lalu lintas yaitu mengukur lebar jalan, dan median jalan jika ada disetiap persimpangan, survei geometrik lalu lintas dilakukan pada saat keadaan persimpang sepi dari arus lalu lintas agar saat mengukur geometrik lalu lintas aman dan nyaman

3. Data primer

Data primer didapatkan dengan cara saat melakukan survei dilapangan untuk mendapatkan data sebagai berikut:

a. Data arus lalu lintas

b. Data geometrik lalu lintas

4. Data sekunder

Data yang diperoleh dari instansi-instansi terkaiti dengan penelitian yaitu mendapatkan data sebagai berikut:

a. Badan pusat statistik kota jambi

\section{Analisa data}

Analisa data merupakan tahap dimana data hasil survei dihitung atau dianalisis menggunakan Manual Kapasitas Jalan Indonesia (MKJI 1997).

\section{Waktu Penelitian}

Waktu penelitian dilakukan selama dua hari maksud dan tujuan mengambilan dua hari ialah mewakli hari libur dan waktu kerja untuk survei arus lalu intas dan survei geometrik jalan dilakukan saat keadaan jalan sepi dari arus lalu lintas. 
William Noferi, Amsori M. Das dan Ari Setiawan, Kinerja Simpang Empat Bersinyal Jalan Depati Purbo Dan Jalan KH. A. Majid

\section{HASIL DAN PEMBAHASAN}

\section{Karakteristik Lalu Lintas}

Data Arus Lalu Lintas

Dari hasil survei Arus Lalu Lintas Simpang Empat Jalan Depati Purbo dan Jalan KH. A. Majid pengambilan data arus lalu lintas dilaksanakan selama dua hari yaitu minggu, 09 Agustus 2020 dan senin, 10 Agustus 2020 survei arus lalu lintas pada Simpng Empat Jalan Depati Purbo dan Jalan KH. A. Majid ini dilakukan dengan mencatat secara langsung dilapangan dengan mengabil waktu pukul 07.00-10.00 wib, pukul 11.00-14.00 wib dan pukul 16.00-19.00 wib. Pengamatan ini dilakukan untuk mengetahui arus dan volume lalu lintas.

Tabel 1. Data Arus Lalu Lintas Mingg,09 Agustus 2020

\begin{tabular}{|c|c|c|c|}
\hline \multicolumn{4}{|c|}{ Jl. Depati Purbo } \\
\hline & $\mathrm{HV}$ & $\mathrm{LV}$ & $\mathrm{MC}$ \\
\hline Waktu & Kend/jam & Kend/jam & Kend/jam \\
\hline $07.00-10.00$ & 0 & 208 & 389 \\
\hline $11.00-14.00$ & 0 & 176 & 305 \\
\hline $16.00-19.00$ & 0 & 293 & 497 \\
\hline \multicolumn{4}{|c|}{ Jl. Jambi - Muara Bulian } \\
\hline \multirow{2}{*}{ Waktu } & $\mathrm{HV}$ & $\mathrm{LV}$ & $\mathrm{MC}$ \\
\hline & Kend/jam & Kend/jam & Kend/jam \\
\hline $07.00-10.00$ & 69 & 449 & 1620 \\
\hline $11.00-14.00$ & 53 & 417 & 1297 \\
\hline $16.00-19.00$ & 88 & 684 & 1753 \\
\hline \multicolumn{4}{|c|}{ Jl. KH. A. Majid } \\
\hline \multirow{2}{*}{ Waktu } & $\mathrm{HV}$ & $\mathrm{LV}$ & $\mathrm{MC}$ \\
\hline & $\mathrm{Kend} /$ jam & Kend/jam & $\mathrm{Kend} / \mathrm{jam}$ \\
\hline $07.00-10.00$ & 6 & 574 & 1761 \\
\hline $11.00-14.00$ & 6 & 433 & 1304 \\
\hline $16.00-19.00$ & 21 & 684 & 1897 \\
\hline \multicolumn{4}{|c|}{ Jl. Jambi - Riau } \\
\hline \multirow{2}{*}{ Waktu } & $\mathrm{HV}$ & $\mathrm{LV}$ & $\mathrm{MC}$ \\
\hline & Kend/jam & Kend/jam & Kend/jam \\
\hline $07.00-10.00$ & 50 & 610 & 1725 \\
\hline $11.00-14.00$ & 25 & 435 & 1297 \\
\hline $16.00-19.00$ & 56 & 755 & 1859 \\
\hline
\end{tabular}

Sumber : Survei lapangan, 2020.

Tabel 2. Data Arus Lalu Lintas Senin ,10 Agustus 2020

\begin{tabular}{|c|c|c|c|}
\hline \multicolumn{4}{|c|}{ Jl. Depati Purbo } \\
\hline & HV & LV & $\mathrm{MC}$ \\
\hline Waktu & Kend/jam & Kend/jam & Kend/jam \\
\hline $07.00-10.00$ & 0 & 193 & 468 \\
\hline $11.00-14.00$ & 0 & 222 & 375 \\
\hline $16.00-19.00$ & 0 & 300 & 612 \\
\hline \multicolumn{4}{|c|}{ Jl. Jambi - Muara Bulian } \\
\hline \multirow{2}{*}{ Waktu } & $\mathrm{HV}$ & LV & $\mathrm{MC}$ \\
\hline & Kend/jam & Kend/jam & Kend/jam \\
\hline $07.00-10.00$ & 112 & 592 & 1747 \\
\hline $11.00-14.00$ & 53 & 502 & 1390 \\
\hline $16.00-19.00$ & 70 & 727 & 1913 \\
\hline \multicolumn{4}{|c|}{ Jl. KH. A. Majid } \\
\hline \multirow{2}{*}{ Waktu } & $\mathrm{HV}$ & LV & $\mathrm{MC}$ \\
\hline & Kend/jam & Kend/jam & Kend/jam \\
\hline $07.00-10.00$ & 7 & 576 & 1859 \\
\hline $11.00-14.00$ & 0 & 509 & 1404 \\
\hline $16.00-19.00$ & 23 & 721 & 1994 \\
\hline \multicolumn{4}{|c|}{ Jl. Jambi - Riau } \\
\hline & $\mathrm{HV}$ & $\mathrm{LV}$ & $\mathrm{MC}$ \\
\hline waktu & Kend/jam & Kend/jam & Kend/jam \\
\hline $07.00-10.00$ & 51 & 704 & 1871 \\
\hline $11.00-14.00$ & 20 & 473 & 1600 \\
\hline $16.00-19.00$ & 58 & 805 & 2017 \\
\hline
\end{tabular}

Sumber : Survei lapangan, 2020 
Keterangan tabel 4.1 dan tabel 4.2:

$\mathrm{HV}=$ Kendaraan berat

$\mathrm{LV} \quad=$ Kendaraan ringan

MC = Kendaraan sepeda motor

Survei arus lalu lintas yang di lakukan pada hari Minggu, 09 Agustus 2020 dan Senin, 10 Agustus 2020 dapat di ketahui jam-jam pncak pada Jl. Depati Purbo terjadi pada hari Senin, 10 Agustus 2020 pukul 16.00-19.00, Jl. JambiMuara Bulian pada hari Senin, 10 Agustus 2020, Jl. KH. A. Majid pada hari Senin pukul 16.00-19.00 dan Jl. JambiRiau pada hari Senin, 10 Agustus 2020. Selanjutnya data lalu lintaslah ini yang akan dianlisis.berdasrkan arus lalu lintas jam puncak menurut jenis kendaraan dan arah pergerakan dalam satuan kend./jam.

\section{Waktu Siklus}

Menghitung waktu siklus dapat dilihat di bawah ini

$\mathrm{c} \quad=(1,5 \times \mathrm{LTI}+5) /\left(1-\sum \mathrm{FR}\right)$

c $\quad=(1.5 \times 16+5) /(1-0.753409)=117 \mathrm{det}$

\section{Arus Lalu Lintas Q}

Untuk menghitung arus lalu lintas $Q$ dapat menggunakan persamaan dibawah ini $\mathrm{Q}(\mathrm{RT} . \mathrm{ST} . \mathrm{LT})=\left(\mathrm{Q}_{\mathrm{LV}} \times \mathrm{emp}_{\mathrm{LV}}\right)_{+}\left(\mathrm{Q}_{\mathrm{HV}} \times \mathrm{emp}_{\mathrm{HV}}\right)+\left(\mathrm{Q}_{\mathrm{MC}} \times \mathrm{emp}_{\mathrm{MC}}\right)$

Tabel 3. Hasil Perhitungan Nilai Arus Lalu lintas Q

Sumber : Data olahan, 2020

\begin{tabular}{cc}
\hline Pendekat & Smp/jam \\
\hline Jl. Depati Purbo & 422.4 \\
Jl. Jambi-Muara Bulian & 1200.6 \\
Jl. KH. A. Majid & 1149.7 \\
Jl. Jambi-Riau & 1283.8 \\
\hline
\end{tabular}

\section{Rasio Kendaraan Belok Kiri $\mathbf{P}_{\mathrm{LT}}$}

Untuk menghitung rasio kendaraan beok kiri $\left(\mathrm{P}_{\mathrm{LT}}\right)$ dapat menggunakan persamaan dibawah ini :

$\mathrm{P}_{\mathrm{LT}}=\frac{\mathrm{Q}_{\mathrm{LT}}(\mathrm{smp} / \mathrm{jam})}{\mathrm{Q}_{\mathrm{TOT}} \mathrm{LL}(\mathrm{smp} / \mathrm{jam})}$

Sumber : Data olahan, 2020

Tabel 4. Hasil Perhitungan Rasio Kendaraan Belok Kiri $\mathrm{P}_{\mathrm{LT}}$

\begin{tabular}{cc}
\hline Pendekat & PLT \\
\hline Jl. Depati Purbo & 0.343 \\
Jl. Jambi-Muara Bulian & 0.106 \\
Jl. KH. A. Majid & 0.407 \\
Jl. Jambi-Riau & 0.445 \\
\hline
\end{tabular}

\section{Rasio Kendaraan Belok Kanan $\mathbf{P}_{\mathrm{RT}}$}

Untuk menghitung rasio kendaraan beok kiri $\left(\mathrm{P}_{\mathrm{RT}}\right)$ dapat menggunakan persamaan dibawah ini :

$\mathrm{P}_{\mathrm{RT}}=\frac{\mathrm{Q}_{\mathrm{RT}}(\mathrm{smp} / \mathrm{jam})}{\mathrm{Q}_{\mathrm{TOTAL}}(\mathrm{smp} / \mathrm{jam})}$

Sumber : Data olahan, 2020

Tabel 5. Hasil Perhitungan Rasio Kendaraan Belok Kanan $P_{R T}$

\begin{tabular}{cc}
\hline Pendekat & PRT \\
\hline Jl. Depati Purbo & 0.346 \\
Jl. Jambi-Muara Bulian & 0.378 \\
Jl. KH. A. Majid & 0.454 \\
Jl. Jambi-Riau & 0.096 \\
\hline
\end{tabular}

\section{Rasio Kendaraan Tak Bermotor $\mathbf{P}_{\mathrm{UM}}$}

Untuk menghitung rasio kendaraan tak bermotor dapat melihat persamaan dibawah ini

$\mathrm{P}_{\mathrm{UM}}=\frac{\mathrm{Q}_{\mathrm{UM}}}{\mathrm{Q}_{\mathrm{MV}}(\text { Kend./jam })}$ 
William Noferi, Amsori M. Das dan Ari Setiawan, Kinerja Simpang Empat Bersinyal Jalan Depati Purbo Dan Jalan KH. A. Majid

Tabel 6. Hasil Perhitungan Rasio Kendaraan Tak Bermotor $\mathrm{P}_{\mathrm{UM}}$

\begin{tabular}{cc}
\hline Pendekat & PUM \\
\hline Jl. Depati Purbo & 0.003 \\
Jl. Jambi-Muara Bulian & 0 \\
Jl. KH. A. Majid & 0.001 \\
Jl. Jambi-Riau & 0.001 \\
\hline
\end{tabular}

Sumber : Data olahan, 2020

\section{Kondisi Geometrik dan Kondisi Lingukungan}

Arus Jenuh Dasar ( $\left.\mathbf{S}_{\mathbf{o}}\right)$

Arus jenuh dasar merupakan besarnya keberangkatan antrian didalam pendekat selama kondisi ideal (smp/jam hijau).

$\mathrm{S}_{\mathrm{O}}=780 \times \mathrm{We}$

Tabel 7. Hasil Perhitungan Arus Jenuh Dasar $S_{0}$

\begin{tabular}{cc}
\hline Pendekat & S0 (smp/jam hijau) \\
\hline Jl. Depati Purbo & 5460 \\
J1. Jambi-Muara Bulian & 6420 \\
Jl. KH. A. Majid & 6420 \\
Jl. Jambi-Riau & 6420 \\
\hline
\end{tabular}

Sumber : Data olahan, $2 \overline{020}$

Faktor Koreksi Belok Kanan F $_{\text {RT }}$

Untuk menghitung faktor koreksi belok kanan $\mathrm{F}_{\mathrm{RT}}$ tanpa median dapat dihitung dengan rumus di bawah ini $\mathrm{F}_{\mathrm{RT}}=1+\mathrm{P}_{\mathrm{RT}} \times 0.26$

Tabel 8. Hasil Perhitungan Faktor Koreksi Belok Kanan $F_{R T}$

\begin{tabular}{cc}
\hline Pendekat & FRT $_{\mathbf{R}}$ \\
\hline Jl. Depati Purbo & 1.090 \\
Jl. Jambi-Muara Bulian & 1.098 \\
Jl. KH. A. Majid & 1.118 \\
Jl. Jambi-Riau & 1.025 \\
\hline
\end{tabular}

Sumber : Data olahan, 2020

Faktor Koreksi Belok Kiri $\mathbf{F}_{\mathbf{L T}}$

Untuk menghitung faktor koreksi belok kiri $\mathrm{F}_{\mathrm{LT}}$ tanpa median dapat dihitung dengan rumus di bawah ini $\mathrm{F}_{\mathrm{LT}}=1+\mathrm{P}_{\mathrm{LT}} \times 0.16$

Tabel 9. Hasil Perhitungan Faktor Koreksi Belok Kiri F LT

\begin{tabular}{cc}
\hline Pendekat & FLT $_{\mathbf{L T}}$ \\
\hline Jl. Depati Purbo & 1.054 \\
J1. Jambi-Muara Bulian & 1.017 \\
J1. KH. A. Majid & 1.065 \\
J1. Jambi-Riau & 1.071 \\
\hline
\end{tabular}

Sumber : Data olahan, 2020

\section{Kinerja Simpang \\ Kapasitas}

Kapasitas adalah arus lalu lintas yang dapat menampung oleh suatu pendekat dalam waktu tertentu untuk menentukan kapasitas dapat dilihat rumus dibawah ini.

$\mathrm{C}=\mathrm{S} \times \mathrm{g} / \mathrm{c}$

Tabel 10. Hasil Perhitungan Nilai Kapasitas

\begin{tabular}{cc}
\hline Pendekat & C \\
\hline Jl. Depati Purbo & $497.098 \mathrm{smp} /$ jam \\
Jl. Jambi-Muara Bulian & $1379.731 \mathrm{smp} / \mathrm{jam}$ \\
Jl. KH. A. Majid & $1323.816 \mathrm{smp} / \mathrm{jam}$ \\
Jl. Jambi-Riau & $1446.613 \mathrm{smp} / \mathrm{jam}$ \\
\hline
\end{tabular}

Sumber : Data olahan, 2020 
William Noferi, Amsori M. Das dan Ari Setiawan, Kinerja Simpang Empat Bersinyal Jalan Depati Purbo Dan Jalan KH. A. Majid

\section{Derajat Kejenuhan}

Untuk menentukan nilai kapasitas dipakai untuk menghitung derajat kejenuhan dapat melihat rumus dibawah ini

$\mathrm{DS}=\mathrm{Q} / \mathrm{C}$

.Tabel 11. Hasil Perhitungan Derajat Kejenuhan

\begin{tabular}{cc}
\hline Pendekat & DS \\
\hline Jl. Depati Purbo & 0.849 \\
J1. Jambi-Muara Bulian & 0.870 \\
Jl. KH. A. Majid & 0.868 \\
Jl. Jambi-Riau & 0.868 \\
\hline
\end{tabular}

Sumber : Data olahan, $202 \overline{0}$

\section{Panjang Antrian}

Untuk keperluaan perencanaan, manual mungkin untuk penyesuian dari nilai rata-rata ini ketingkat peluang pembebanan lebih yang dikehendaki.

Panjang antrian (QL) diperoleh dari perkalian (NQ) dengan luas rata-rata yang dipergunakan per smp $\left(20 \mathrm{~m}^{2}\right)$ dan pembagian dengan lebar masuk.

$\mathrm{QL}=\frac{\mathrm{NQ}_{\mathrm{MAX} \times 20}}{\mathrm{~W}_{\text {MASUK }}}$

Tabel 12. Hasil Perhitungan Panjang Antrian QL

\begin{tabular}{cc}
\hline Pendekat & QL \\
\hline Jl. Depati Purbo & $137 \mathrm{~m}$ \\
J1. Jambi-Muara Bulian & $290 \mathrm{~m}$ \\
Jl. KH. A. Majid & $270 \mathrm{~m}$ \\
Jl. Jambi-Riau & $295 \mathrm{~m}$ \\
\hline
\end{tabular}

Sumber : Data olahan, 2020

\section{Angka Henti}

Angka henti (NS) yaitu jumlah berhenti rata-rata perkendaraan (termasuk berhenti terulang dalam antrian) sebelum melewati suatu simpang (MKJI 1997), dihitung sebagai berikut:

Untuk menghitung kendaraan terhenti $\mathrm{N}_{\mathrm{Sv}}$, adalah rasio kendaraan yang harus berhenti akibat sinyal merah sebelum melewati suatu simpang, I dihitung sebagai:

$\mathrm{N}_{\mathrm{SV}}=\mathrm{Q} \times \mathrm{NS} \mathrm{smp} / \mathrm{jam}$

Tabel 13. Hasil Perhitungan Angka Henti $\mathrm{N}_{\mathrm{SV}}$

\begin{tabular}{cc}
\hline Pendekat & Nsv \\
\hline Jl. Depati Purbo & $434.227 \mathrm{smp} /$ jam \\
Jl. Jambi-Muara Bulian & $1110.555 \mathrm{smp} / \mathrm{jam}$ \\
Jl. KH. A. Majid & $1070.371 \mathrm{smp} / \mathrm{jam}$ \\
Jl. Jambi-Riau & $1200.353 \mathrm{smp} / \mathrm{jam}$ \\
\hline
\end{tabular}

Sumber : Data olahan, 2020

\section{Tundaan}

\section{Tundaan Rata-Rata}

Tundaan rata-rata untuk suatu pendekat dihitung sebagai:

$\mathrm{D}=\mathrm{DT}+\mathrm{DG}$

Tabel 14. Hasil Perhitungan Tundaan Rata rata D

\begin{tabular}{cc}
\hline Pendekat & D \\
\hline Jl. Depati Purbo & $52.054 \mathrm{det} / \mathrm{smp}$ \\
J1. Jambi-Muara Bulian & $52.748 \mathrm{det} / \mathrm{smp}$ \\
Jl. KH. A. Majid & $54.893 \mathrm{det} / \mathrm{smp}$ \\
Jl. Jambi-Riau & $52.914 \mathrm{det} / \mathrm{smp}$ \\
\hline
\end{tabular}

Sumber : Data olahan, 2020 


\section{SIMPULAN}

Berdasarkan dari hasil analisis data penelitian yang telah dilakukan di Simpang Empat Jl. Depati Purbo dan Jl. KH. A. Majid dapat diambil beberapa kesimpulan sebagai berikut :

1. Karakteristik lalu lintas, Arus lalu lintas jam puncak terjadi pada Jl. Jambi-Riau sebesar $1283.8 \mathrm{smp} / \mathrm{jam}$ pada tanggal 10 Agustus 2020 pukul 16.00 wib -19.00 wib dan nilai waktu siklus sebesar 117 detik.

2. Kininerja Simpang Empat Jl. Depati Purbo dan Jl. KH. A. Majid dapat dilihat dari nilai kapasitas (C) (Jl. Depati Purbo 497.098smp/jam), kapasitas (C) (Jl. Jambi-Muara Bulian 1379.731 smp/jam), kapasitas (C) (Jl. KH. A. Majid 1323.816 smp/jam), kapasitas (C) (Jl. Jambi- Riau 1446.613 smp/jam).

3. Derajat kejenuhan simpang yang cukup tinggi (DS) (Jl. Jambi- Riau 0.887), (DS) (Jl. Jambi-Muara Bulian 0.870169), (DS) (Jl. KH. A. Majid 0.868), (DS) (Jl. Depati Purbo 0.849).

4. Panjang antrian (QL) (Jl. Depati Purbo 137 m) (QL) (Jl. Jambi-Muara Bulian 290 m) (QL) (Jl. KH. A. Majid270 m) (QL) (Jl. Jambi- Riau 295 m).

5. Jumlah kendaraan terhenti $\left(\mathbf{N}_{\mathbf{S v}}\right)$ (Jl. Depati Purbo 434.227 smp/jam), ( $\mathbf{N}_{\text {Sv }}$ ) (Jl. Jambi-Muara Bulian 1111.555 smp/jam), (Nsv) (Jl. KH. A. Majid 1070.371 smp/jam), (Nsv) (Jl. Jambi- Riau 1200.353 smp/jam).

6. Tundaan rata-rata ,(D) (Jl. Depati Purbo 52.054 det/smp), (D) (Jl. Jambi-Muara Bulian 52.748 det/smp), (D) (Jl. KH. A. Majid 54.983 det/smp), (D) (Jl. Jambi-Muara Bulian 52.914 det/smp).

\section{Saran}

Berdasarkan analisis dari kesimpulan yang telah dilakukan, maka saran yang dapat disampaikan adalah.

1. Perlu adanya perhatian yang serius yaitu pengaturan lalu lintas maupun kondisi geometrik dan lingkungan pada simpang tersebut agar panjang antrian dan tundaan dapat dikurangi.

2. Perlu adanya sosialisasi tentang mematuhi peraturan rambu lalu lintas untuk keamanan dan kenyaman berlalulintas.

3. Perlu diadakan penelitian selanjutnya tentang kinerja simpang empat jalan depati purbo dan jalan KH. A. Majid yang meliputi kapasitas, derajat kejenuhan, panjang antrian dan tundaan karena kinerja simpang tersebut tidak memenuhui syarat dari MKJI 1997.

\section{DAFTAR PUSTAKA}

Badan Pusat Statistik Kota Jambi, 2019. Jumlah Penduduk Kota Jambi Menurut Kecamatan, Jenis Kelamin dan Rasio Jenis Kelamin 2013-2018. Kota Jambi: Badan Pusat Statistik.

Ikrar Tulus, Muh. 2018. "Analisa Simpang Bersinyal Kota Makasar Menggunakan Quantum Gis". Tugas Akhir. Teknik. Tekinik Sipil. Universitas Hasanudin, Makasar.

Khisty, Jotin C. B. Kent Lall. 2005. Dasar-dasar Rekayasa Transfortasi. Jakarta: Erlangga.

Republik Indonesia Direkctorat Jendral Bina Marga Direktorat Bina Jalan Kota (Binkot). 1997. Manual Kapasitas Jalan Indonesia (MKJI). Jakarta. 